\title{
Validated HPTLC Method for Simultaneous Quantitation of Aceclofenac, Paracetamol and Thiocolchicoside in Bulk drug and Pharmaceutical Formulation
}

\author{
J. Saminathan ${ }^{1 *}$, S. Sivakalai ${ }^{2}$, T. Vetrichelvan ${ }^{3}$ \\ ${ }^{1}$ Delhi Pharmaceutical Sciences \& Research University, Govt of NCT of Delhi, New Delhi- 110017 \\ ${ }^{2}$ Annamalai University, Chidambaram, Tamilnadu \\ ${ }^{3}$ Adhiparasakthi College of Pharmacy, Melmaruvathur-603319 Tamilnadu
}

\begin{abstract}
A simple high performance thin layer chromatographic method for simultaneous quantification of aceclofenac, paracetamol and thiocolchicoside in bulk and tablet dosage form was investigated. Chromatographic separation of the drugs were performed on aluminium plates precoated with silica gel $60 \mathrm{~F}_{254}$ as the stationary phase and the solvent system consisted of chloroform: methanol: ethyl acetate: glacial acetic acid (5: 2.5: 2.5: 0.1 , $\mathrm{v} / \mathrm{v} / \mathrm{v} / \mathrm{v}$ ). Densitometric evaluation of the separated zones was performed at $272 \mathrm{~nm}$ and the method was validated. The $\mathrm{R}_{f}$ values and drug content of aceclofenac, paracetamol and thiocolchicoside were $0.52 \pm 0.03,0.72 \pm 0.03$ and $0.30 \pm 0.03$ and $100.37 \%, 100.30 \%$ and $100.43 \%$ respectively. The calibration curves of peak area versus concentration, which were linear from $50-300 \mathrm{ng} / \mathrm{b}$ and of aceclofenac, $250-1500 \mathrm{ng} / \mathrm{band}$ of paracetamol and 50 $300 \mathrm{ng} / \mathrm{band}$ of thiocolchicoside, coefficient of determination $\left(\mathrm{r}^{2}\right)$ was greater than 0.999 . The method was validated for linearity, accuracy, precision, robustness, specificity and application for assay as per ICH guidelines.
\end{abstract}

Keyword: HPTLC, Method development, Validation, Aceclofenac, Paracetamol, Thiocolchicoside, ICH guidelines

\section{INTRODUCTION}

Aceclofenac (ACE), chemically 2-[2[2-[(2,6-dichlorophenyl)amino]phenyl]acetyl] oxyacetic acid (Fig.1 A), is non-steroidal antiinflammatory drug (NSAID) used for relief of pain and inflammation in osteoarthritis, rheumatoid arthritis and ankylosing spondylitis. Paracetamol (PAR), chemically 4-hydroxy acetanilide (Fig.1B), is centrally and peripherally acting non-opioid analgesic and antipyretic. Thiocolchicoside (THIO) is $N$-[(7S)-3-(beta-D-glucopyranosyloxy) -1,2-dimethoxy-10(methylsulfanyl)-9-oxo-5,6,7,9 -tetrahydrobenzo[a] heptalen-7-yl] acetamide (Fig.1C) is a muscle relaxant, used in the symptomatic treatment with anti-inflammatory and analgesic actions ${ }^{1-5}$.
Extensive literature review reveals that several $U^{6-9}$ and HPLC ${ }^{10-11}$ methods have been reported for the estimation in binary and combined form with other drugs, but no HPTLC method is reported. some advantages over UV, HPLC methods include more rapid separation, better resolution and more sensitive detection $(5-10$ fold), without need for prior extraction. This method may help to minimizes exposure risk of toxic organic effluents and significantly reduces its disposal problems consequently, reducing environment pollution ${ }^{12}$. It provides simple, direct and rapid quantitation. The efficiency of separation is poorer compared to HPLC. The proposed method was validated in accordance with International conference on harmonisation (ICH) guidelines ${ }^{13-15}$. 

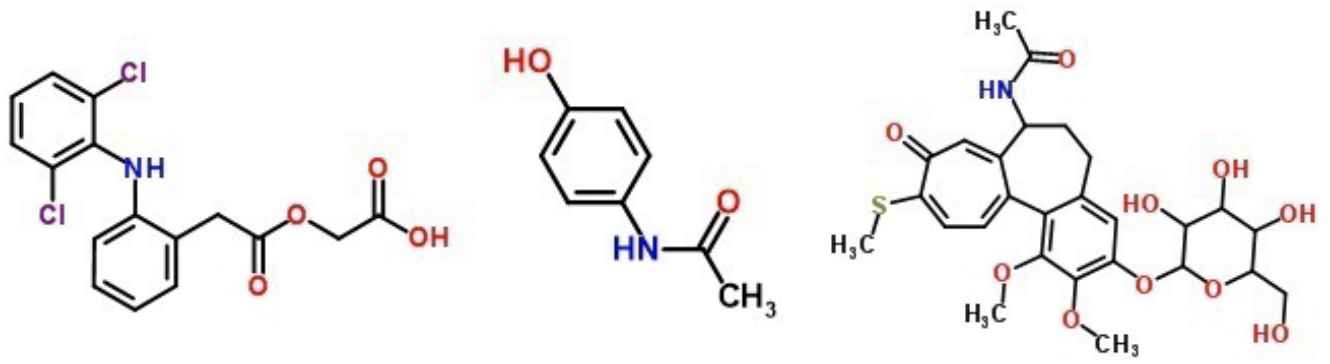

Figure 1. Structural formula of A) aceclofenac B) paracetamol C) thiocolchicoside

\section{MATERIALS AND METHODS}

\subsection{Instrumentation}

The samples were spotted in the form of bandwidth of width $6 \mathrm{~mm}$ with a Camag $100 \mu \mathrm{L}$ sample syringe (Hamilton, Bonded, Switzerland) on silica gel precoated aluminum plate $60 \mathrm{~F}$ 254 plates, $[10 \mathrm{~cm} \times 10 \mathrm{~cm}$ with $250 \mu \mathrm{m}$ thickness; E.Merck, Darmstadt, Germany] using a Camag Linomat V (Switzerland) sample applicator. Linear ascending development was carried out in a $10 \mathrm{~cm} \times 10 \mathrm{~cm}$ twin trough glass chamber (Camag, Muttenz, Switzerland) saturated with the mobile phase. The saturation time was kept more than an ideal time $(30 \mathrm{~min})$ because of less amount of organic solvent present in the mobile phase used for chromatography run. Following the development, TLC plates were dried in a stream of air with the help of an air dryer in a wooden chamber with adequate ventilation. Densitometric scanning was performed using a Camag TLC scanner III in the reflectance absorbance mode at $272 \mathrm{~nm}$ and operated by winCATS software (V 3.15, Camag). Evaluation was performed by linear regression of peak areas.

\subsection{Chemicals and reagents}

Working standards of pharmaceutical grade aceclofenac, paracetamol and thiocolchicoside were obtained as generous gifts from Accent Pharmaceuticals Ltd, Puduchery, India. Samples were used without further purification and certified to contain $99.96 \%, 99.98 \%$ and $99.99 \%(\mathrm{w} / \mathrm{w})$ on dry weight basis for aceclofenac, paracetamol and thiocolchicoside. Fixed dose combination tablets (Brand Name: Bakflex Plus) containing $100 \mathrm{mg}$ of aceclofenac, $500 \mathrm{mg}$ of paracetamol and $4 \mathrm{mg}$ of thiocolchicoside procured from local market. All chemicals and reagents of analytical grade were purchased from Merck Chemicals, Mumbai, India.

\subsection{Optimization of HPTLC method}

Initially, ethylacetate and methanol in the ratio of $1: 1(\mathrm{v} / \mathrm{v})$ was tried for all drugs simultaneously. The spots were not developed properly and dragging was observed. Then, chloroform: methanol: ethyl acetate in the ratio of 5:2.5:2.5 (v/v/v) were tried. The developed spots were diffused to the above mobile phase; $0.1 \mathrm{~mL}$ glacial acetic acid was added. Both the peaks were symmetrical in nature and tailing was observed. To improve resolution, the volume of glacial acetic acid was increased. Ultimately, mobile phase consisting of chloroform: methanol: ethyl acetate: glacial acetic acid (5: 2.5: 2.5 : $0.1, \mathrm{v} / \mathrm{v} / \mathrm{v} / \mathrm{v}$ ) gave good resolution at $272 \mathrm{~nm}$. The chamber was saturated with the mobile phase for $20 \mathrm{~min}$ at room temperature and plates were activated at $110^{\circ} \mathrm{C}$ for $5 \mathrm{~min}$ to obtain well defined peak.

\subsection{Preparation of standard stock solution}

Accurately weigh and transfer $50 \mathrm{mg}$ of aceclofenac, $125 \mathrm{mg}$ of paracetamol and 50 $\mathrm{mg}$ of thiocolchicoside working standards into a $50 \mathrm{~mL}$ clean dry volumetric flask, add about $10 \mathrm{~mL}$ of methanol and make volume up to the mark with the same methanol. Further pipette out $0.5 \mathrm{ml}$ of aceclofenac, $1 \mathrm{ml}$ of paracetamol, and $0.5 \mathrm{ml}$ of thiocolchicoside from above stock solution into $10 \mathrm{~mL}$ volumetric flask and 
dilute up to the mark with diluents. from this serial dilutions, $1-6 \mu 1$ were applied on silicagel $60 \mathrm{~F}_{254}$ aluminum sheets. concentration range selected were $50-300 \mathrm{ng} / \mu \mathrm{l}$ for aceclofenac, $250-1500 \mathrm{ng} / \mu \mathrm{l}$ for paracetamol and $50-300$ $\mathrm{ng} / \mu \mathrm{l}$ for thiocolchicoside.

\subsection{Preparation of sample solution}

Twenty tablets were accurately weighed and crushed into a fine powder in a mortar. The proportion of thiocolchicoside in the tablet is very low; to increase the accuracy of the method about $4.6 \mathrm{mg}$ of thiocolchicoside was added by standard addition method.An amount of powder equivalent to $50 \mathrm{mg}$ of paracetamol added $9.6 \mathrm{mg}$ of thiocolchicoside working standard transferred into a $10 \mathrm{ml}$ volumetric flask, added about $7 \mathrm{ml}$ of methanol, sonicated for 20 minutes and made up to the mark with methanol. The solution was centrifuged at $2000 \mathrm{rpm}$ for 10 minutes and filtered through $0.45 \mu \mathrm{m}$ filter paper. $0.5 \mathrm{~mL}$ of the above solution was diluted to $10 \mathrm{ml}$ with methanol. $2 \mu$ quantity of the sample was spotted six times under optimized chromatographic conditions. and the densitogram was recorded. The amount was calculated from the regression equation of the calibration graph. The peak areas were measured at $272 \mathrm{~nm}$.

\subsection{Method validation}

The method was validated in accordance with ICH guidelines. The parameters assessed were linearity, accuracy, limit of detection (LOD), limit of quantification (LOQ), precision, specificity and robustness.

\subsubsection{Linearity}

Six different concentrations of the mixed standard drugs of aceclofenac, paracetamol and thiocolchicoside were prepared for linearity studies and injected in to system $(n=6)$. The response was measured as peak areas. Each concentration was prepared from individual stock solution. The plate was then developed by using mobile phase by keeping the injection volume constant. The peak areas were plotted against concentrations to obtain the calibration curve.

\subsubsection{Accuracy}

The accuracy was carried out by adding known amounts of each analyte corresponding to three concentration levels (80, 100 and 120\%) of the labeled claim to the excipients. At each level, six determinations were performed and the results were recorded. Accuracy was expressed as percent analyte recovered by the proposed method.

\subsubsection{Precision}

The precision of analytical method is the degree of agreement among the individual test results, when the method is applied repeatedly to multiple sampling of homologous samples. The precision of the method was checked by repeatability of injection, repeatability (intraday), intermediate precision (inter-day) and reproducibility. repeatability was studied by calculating the percentage relative standard deviation ( $\%$ RSD) for six determination of peak areas of aceclofenac, paracetamol and thiocolchicoside, performed on the same day. For both intra-day and inter-day variations standard solutions were injected six times for each concentration.

\subsubsection{Detection limit and quantification limit}

The limit of detection (LOD) and limit of quantification (LOQ) were calculated according to Equation $1 \& 2$, respectively.

$\mathrm{LOD}=3.3(\mathrm{SD}) / \mathrm{S}$
$\mathrm{LOQ}=10(\mathrm{SD}) / \mathrm{S}$.

Where SD is the standard deviation of response (peak area) and $\mathrm{S}$ is the average of the slope of the calibration curve.

\subsubsection{Specificity}

The ability of an analytical method to unequivocally assess the analyte in the presence of other components can be demonstrated by evaluating specificity.The specificity of the method was determined by analyzing standard drug and test samples. The spot for aceclofenac, paracetamol and thiocolchicoside in the samples was confirmed by comparing the $\mathrm{R}_{f}$ and spectrum 
of the spot with that of a standard. The peak purity of aceclofenac, paracetamol and thiocolchicoside was determined by comparing the spectrum at three different regions of the spot, that is, peak start $(S)$, peak apex $(M)$ and peak end $(E)$.

\subsubsection{Robustness}

Robustness was assessed by introducing small changes in the mobile phase composition and measuring the effects of result, mobile phase. The amount of mobile phase was varied by $\pm 0.5 \mathrm{~mL}$; the plates were pre-washed with methanol and activated at $60 \pm 5^{\circ} \mathrm{C}$ for 2,5 and 7 min before chromatography. Time from application to chromatography and from chromatography to scanning was also varied $(10,20$ and $40 \mathrm{~min})$. The robustness of the method was measured for $100 \mathrm{ng} / \mu \mathrm{l}$ for aceclofenac, $500 \mathrm{ng} / \mu \mathrm{l}$ for paracetamol and $100 \mathrm{ng} / \mu \mathrm{l}$ for thiocolchicoside.

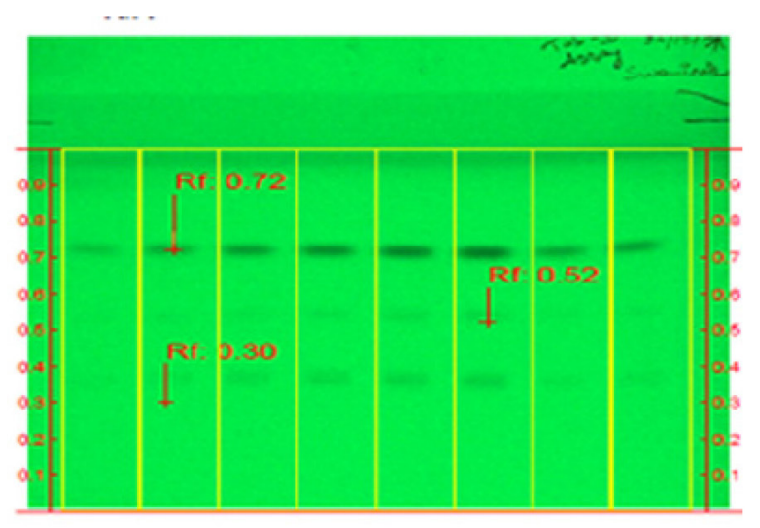

\section{RESULTS AND DISCUSSION}

\subsection{HPTLC method development}

Initial trials were performed with the objective of selecting adequate and optimum chromatographic conditions. such as ideal mobile phase and their proportions, detection wave length and concentrations of the standard solutions were carefully studied. Several solvents were tested in varying proportions. Finally, the optimized mobile phase were chloroform: methanol: ethyl acetate: glacial acetic acid (5: 2.5: 2.5: 0.1, $\mathrm{v} / \mathrm{v} / \mathrm{v} / \mathrm{v}$ ) chromatographic conditions were selected based on sensitivity, $\mathrm{R}_{f}$ values, peak shape and baseline drifts. A typical densitogram recorded at $272 \mathrm{~nm}$ is shown in Fig.2A-B. The $\mathrm{R}_{f}$ values of aceclofenac, paracetamol and thiocolchicoside are $0.52 \pm 0.03,0.72 \pm 0.03$ and $0.30 \pm 0.03$, respectively. The analyte peaks were well resolved.

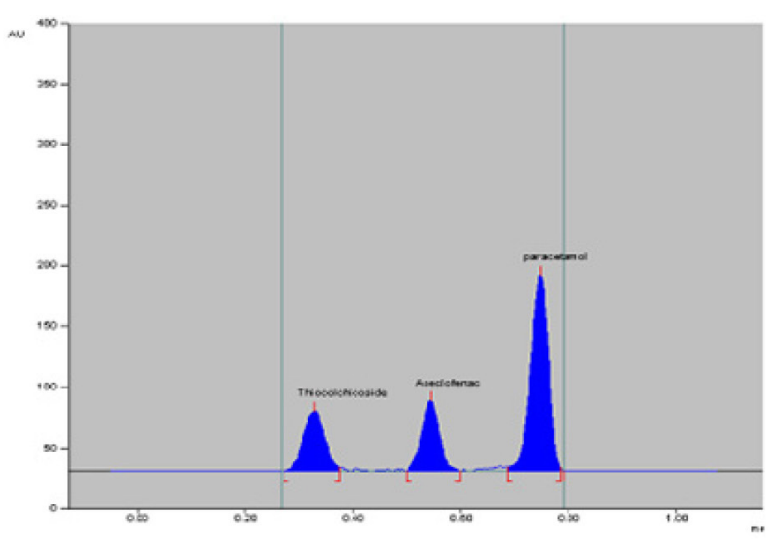

Figure 2. A-B. Typical densitogram of ACE (1), PAR (2) and THIO (3)

\subsection{Method validation}

The developed HPTLC method was validated in terms of linearity, accuracy, precision, LOD, LOQ, robustness and specificity as per ICH guidelines.

\subsubsection{Linearity}

The calibration curve obtained by plotting peak area against concentration showed linearity in the concentration range of 50-300 ng/band of ACE, 250-1500 ng/band of PARA and 50-300 ng/band of THIO. Linear regression data for the calibration curves are given in Table 1.

\subsubsection{Accuracy}

The results of the repeatability and intermediate precision experiments are shown in Table 2. The developed methods were found to be precise as the RSD values for repeatability and intermediate precision studies were $<2 \%$, respectively as recommended by $\mathrm{ICH}$ guidelines. There was no significant difference between the \% RSD values, which indicates that the proposed method was reproducible. 
Table 1. Accuracy and repeatability results

\begin{tabular}{lccc}
\hline \multicolumn{1}{c}{ Parameter } & ACE & PARA & THIO \\
\hline Linear Range (ng per band) & $50-300$ & $250-1500$ & $50-300$ \\
coefficient of determination & 0.9991 & 0.9991 & 0.9992 \\
Slope & 14.2992 & 5.9651 & 16.3571 \\
Intercept & 100.44 & 153.96 & 44.64 \\
LOD (ng per band) & 2.60 & 8.52 & 2.83 \\
LOQ (ng per band) & 7.88 & 25.82 & 8.59 \\
\hline
\end{tabular}

Table 2. Results of accuracy for proposed method $(n=6)$

\begin{tabular}{|c|c|c|c|c|c|c|c|}
\hline \multirow[b]{2}{*}{ Drugs } & \multirow[b]{2}{*}{ Label claim } & \multirow{2}{*}{$\begin{array}{c}\text { Amount } \\
\text { added } \\
\text { (ng) }\end{array}$} & \multirow{2}{*}{$\begin{array}{c}\text { Total } \\
\text { amount } \\
\text { ng }\end{array}$} & \multirow{2}{*}{$\begin{array}{c}\text { Actual } \\
\text { Conc } \\
(\mathrm{ng})\end{array}$} & \multicolumn{3}{|c|}{ For $\operatorname{HPTLC}(\mathrm{n}=6)$} \\
\hline & & & & & $\begin{array}{l}\text { Calculated } \\
\text { conc } \pm \text { S.D }\end{array}$ & $\%$ RSD & Recovery \\
\hline \multirow{3}{*}{$\mathrm{ACE}$} & \multirow{3}{*}{$100 \mathrm{mg}$} & 80 & 180 & 80 & $79.69 \pm 0.38$ & 0.52 & 99.61 \\
\hline & & 100 & 200 & 100 & $99.75 \pm 0.59$ & 0.71 & 99.75 \\
\hline & & 120 & 220 & 120 & $120.65 \pm 1.14$ & 0.92 & 100.54 \\
\hline \multirow[t]{3}{*}{ PARA } & \multirow[t]{2}{*}{$500 \mathrm{mg}$} & 400 & 900 & 400 & $399.10 \pm 0.76$ & 0.88 & 99.77 \\
\hline & & 500 & 1000 & 500 & $501.23 \pm 0.54$ & 0.67 & 100.24 \\
\hline & \multirow{4}{*}{$4 \mathrm{mg}$} & 600 & 1100 & 600 & $600.81 \pm 0.71$ & 0.92 & 100.13 \\
\hline \multirow[t]{3}{*}{ THIO } & & 80 & 180 & 80 & $79.41 \pm 0.47$ & 0.59 & 99.26 \\
\hline & & 100 & 200 & 100 & $99.52 \pm 0.59$ & 0.74 & 99.52 \\
\hline & & 120 & 220 & 120 & $119.95 \pm 1.06$ & 1.22 & 99.95 \\
\hline
\end{tabular}

\subsubsection{Precision}

Results for repeatability and intermediate precision, expressed as \% RSD, results were given in Table 3 . The low values of \% RSD indicate that the method is precise. Reproducibility was checked by analyzing the samples by another analyst using same instrument and same laboratory. There was no significant difference between the \% RSD values, which indicates that the proposed method was reproducible.

Table 3. Precision studies of proposed method $(n=6)$

\begin{tabular}{cccccc}
\hline \multirow{2}{*}{ Drugs } & Conc ng per band & \multicolumn{2}{c}{ Repeatability $(\mathrm{n}=6)$} & \multicolumn{2}{c}{ Intermediate precision } \\
\cline { 3 - 6 } & & Found conc. \pm S.D & $\%$ RSD & Found conc. \pm S.D & \% RSD \\
\hline \multirow{2}{*}{ ACE } & 80 & 79.79 & & 79.77 & \\
& 100 & 99.34 & 0.2379 & 100.38 & 0.5234 \\
\multirow{2}{*}{ PARA } & 120 & 119.67 & & 119.34 & \\
& 400 & 400.05 & & 400.05 & \\
& 500 & 500.13 & 0.2508 & 500.08 & 0.3269 \\
THIO & 600 & 600.52 & & 599.5 & \\
& 80 & 101.8 & & 101.76 & 0.3168 \\
& 100 & 99.5 & 1.1657 & 102 & \\
\hline
\end{tabular}




\subsubsection{Detection limit and quantification limit}

The LOD and LOQ values were 2.60 and $7.88 \mathrm{ng}$ per band for Aceclofenac, 8.52 and $25.82 \mathrm{ng}$ per band for Paracetamol and 2.83 and $8.59 \mathrm{ng}$ per band for Thiocolchicoside. The LOD and LOQ values were very low which indicates that the method is sensitive.

\subsubsection{Specificity}

The peak purity of analyzed drugs was assessed by comparing their respective spectra at peak start, apex and end positions of the peak (Fig. 2A-B). A good correlation ( $r$ value more than 0.999) was obtained for all drugs. Acceptable peak purity and correlation values suggest no interference in the quantification of the five analyzed drugs in sample solutions. This proves that the methods are specific.

\subsubsection{Robustness}

There was no significant change in the peak areas and $\mathrm{R}_{f}$ values of aceclofenac, paracetamol and thiocolchicoside when the composition of mobile phase was varied by $\pm 0.5 \mathrm{~mL}$, variation of time for activation of plates before chromatography and chromatography scanning also varied. The results are showed in Table 4. Therefore, the method was proved to be robust as minor changes in the chromatographic parameters did not bring about any significant changes in peak area and $\mathrm{R}_{f}$ value.

Table 4. Results of robustness for proposed method

\begin{tabular}{lccc}
\hline \multirow{2}{*}{ Parameter studied } & \multicolumn{3}{c}{$\%$ RSD } \\
\cline { 2 - 4 } & ACE & PARA & THIO \\
\hline Mobile phase Composition $( \pm 2 \%)$ & 0.86 & 0.69 & 1.20 \\
Volume of mobile phase $( \pm 5 \%)$ & 0.92 & 0.56 & 0.87 \\
Time from spotting to development $(10 \mathrm{~min})$ & 0.41 & 0.32 & 0.37 \\
Time from development to scanning $(10 \mathrm{~min})$ & 0.78 & 0.83 & 0.63 \\
\hline
\end{tabular}

*\% RSD were calculated from the peak areas of densitograms

\subsection{Quantification of Aceclofenac, Paracetamol and Thiocolchicoside:}

The proposed method was applied result shows that $100.37 \pm 0.3698 \%$ for aceclofenac, $100.30 \pm 0.1468 \%$ for paracetamol and 100.43 $\pm 1.0424 \%$ for thiocolchicoside. The method was selective for the simultaneous determination of aceclofenac, paracetamol and thiocolchicoside without interference from the excipients were shown in the Table 5.

Table 5. Results of sample analysis for proposed method $(n=6)$

\begin{tabular}{ccccc}
\hline Brand & Analyte & $\begin{array}{c}\text { Label claim } \\
\text { per tablet }(\mathrm{mg})\end{array}$ & $\begin{array}{c}\text { \% found } \\
(\mathrm{mean} \pm \mathrm{SD})\end{array}$ & \% RSD \\
\hline \multirow{3}{*}{ Bakflex Plus } & Aceclofenac & 100 & $100.37 \pm 0.3698$ & 0.3684 \\
& Paracetamol & 500 & $100.30 \pm 0.1468$ & 0.1464 \\
& Thiocolchicoside & 4 & $100.43 \pm 1.0424$ & 1.0379 \\
\hline
\end{tabular}




\section{CONCLUSION}

To the best of our knowledge, The mobile phase used in the study consisting of a chloroform: methanol: ethyl acetate: glacial acetic acid $(5: 2.5: 2.5: 0.1, \mathrm{v} / \mathrm{v} / \mathrm{v} / \mathrm{v})$ is considered more simple and environment friendly than the mobile phases used in the reported methods. Obviously, the described HPTLC methods offer selectivity advantage over the previously published spectrophotometric non-separation methods. The developed HPTLC method for aceclofenac, paracetamol and thiocolchicoside is accurate, precise, sensitive and economic and rapid, allowing a high sample throughput necessary for quality control routine analysis with an added advantage of low solvent consumption. The proposed method were validated as per ICH guidelines in bulk form and in pharmaceutical formulations without any interference from the excipients.

\section{ACKNOWLEDGEMENTS}

The authors wishes to thank Accent Pharmaceuticals Ltd., Puduchery, India for providing reference standard of aceclofenac, paracetamol and thiocolchicoside as gift samples.

\section{REFERENCES}

1. Indian pharmacopoeia. Govt. of India, Ghaziabad: The Indian Pharmacopoeia Commission; 2007. $5^{\text {th }}$ edition, volume 2 , p.681.

2. Indian pharmacopoeia. Govt. of India, Ghaziabad: The Indian pharmacopoeia commission; 2007. $5^{\text {th }}$ edition, volume 3 , p. 1514 .

3. Indian pharmacopoeia, Government of India, Ministry of Health \& Family Welfare; The Indian Pharmacoepial Commission; Ghaziabad, 2010; Volume III; pp 2213.

4. HPTLC method development and validation: strategy to minimize methodological Failures. Journal of Food and Drug Analysis, 20(4), 2012, 794-804.

5. Sean C. Sweetman, Martindale, The complete drug reference,2003, 34th edition, p.11,76, 1395.

6. Saraf S, Garg G, Swarnalata Saraf. Simultaneous estimation of Aceclofenac,
Paracetamol and Chlorzoxazone in tablets. Ind J. Pharm. Sci. 2007; 69(5): 692-94.

7. Nikhade, Revankumar D, Thakur, Ashutosh D, et al. Simultaneous Estimation of Paracetamol, Thiocolchicoside and Aceclofenac by UV Spectrophotometer Using Multicomponent Mode Method. Journal of Pharmacy Research. 2011; 4(7): 2297.

8. Gharge D, Pandurang P. Simultaneous estimation of aceclofenac, tramadol hydrochloride and paracetamol by uv spectrophotometric simultaneous equation method from tablet formulation. International Journal of Chemical and Analytical Sciences. 2010; 1(3):58-61.

9. Sohan S Chitlange, Pradeep S Shinde, Ganesh R Pawbake, Sagar B Wankhede. simultaneous estimation of Thiocolchicoside and Aceclofenac in pharmaceutical dosage form by Spectrophotometric and LC method. Der Pharmacia Letter. 2010; 2(2): 86-93.

10. Chandra P, Rathore AS, Lohidasan S, Mahadik KR. Application of HPLC for the Simultaneous Determination of Aceclofenac, Paracetamol and Tramadol hydrochloride in Pharmaceutical Dosage Form. Scientia Pharmaceutica. 2012; 80 (2): 337.

11. Sunil R Dhaneshwar, Kanchan O Raut, Vidhya K Bhusari. Validated HPLC method for simultaneous estimation of paracetamol, aceclofenac and thiocolchicoside in bulk drug and formulation. Research Journal of Pharmaceutical, Biological and Chemical Sciences. 2011; 2(2): 435.

12. HPTLC method development and validation: strategy to minimize methodological Failures. Journal of Food and Drug Analysis, Vol. 20, No. 4, 2012, Pages 794-804.

13. Sethi PD. High Performance Thin Layer Chromatography, Quantitative Analysis of drugs in Pharmaceutical Formulation. New Delhi: CBS Publishers \& Distributors; 2013, 417-418, 1054-57.

14. Renger B,Vegh Z,Ferenczi-Fodor K. Validation of thin layer and high performance Thin layer chromatographic methods. J.Chromatography A. 2011; 1218: 2712-21.

15. ICH, Q2(R1) Validation of Analytical Procedures: Text and Methodology, ICH Harmonized Tripartite Guideline, 2005. 